\title{
Factors Associated with Abdominal Obesity among HIV-infected Adults on Antiretroviral Therapy in Malaysia
}

\author{
Nazisa Hejazi \\ Department of Nutrition and Dietetic, Faculty of Medicine and Health Sciences \\ Universiti Putra Malaysia, 43400, Serdang, Selangor, MALAYSIA \\ Tel: 60-17-280-7485 E-mail: Nazisa_Hejazi@yahoo.com \\ Mary Huang Soo Lee \\ Department of Nutrition and Dietetic, Faculty of Medicine and Health Sciences \\ Universiti Putra Malaysia, 43400, Serdang, Selangor, MALAYSIA \\ Tel: 60-3-8947-2471 E-mail: huang@medic.upm.edu.my \\ Khor Geok Lin \\ Department of Nutrition and Dietetic, Faculty of Medicine and Health Sciences \\ Universiti Putra Malaysia, 43400 Serdang, Selangor, MALAYSIA \\ Tel: 60-3-8947-2460 E-mail: khorgl@medic.upm.edu.my \\ Christopher Lee Kwok Choong \\ Department of Medicine, Hospital Sungai Buloh \\ 47000, Sungai Buloh, Selangor, MALAYSIA \\ Tel: 60-3-6145-4333 ext 2204 E-mail: chrislee@hkl.gov.my
}

\begin{abstract}
Abdominal or central obesity is a common morphological alteration among HIV-infected subjects on antiretroviral treatment. There is concern that this condition places the subjects at risk of cardiovascular disease. This is a cross-sectional study of 334, HIV-infected adult subjects on antiretroviral therapy at a public hospital in Malaysia. It was aimed at determining the association between nutritional factors and abdominal obesity among PLHIV receiving antiretroviral treatment. Abdominal obesity was prevalent in $36.5 \%$ of the respondents. Respondents with abdominal obesity were significantly $(p<0.05)$ older in age, had significantly higher blood triglycerides, fasting plasma glucose, lower HDL-cholesterol, higher BMI at the start of medication and also at the time of the study, bigger waist circumference, higher waist hip ratio, body fat mass, systolic and diastolic blood pressure. They also had lower mean CD4 cell count at start of medication and body lean mass than those without abdominal obesity. After adjusting for the covariates, a significantly higher risk of abdominal obesity was observed in those who were older (adjusted $\mathrm{OR}=1.053, \mathrm{CI}=1.012-1.095$ ), had higher fasting plasma glucose (adjusted $\mathrm{OR}=1.189, \mathrm{CI}=1.014-1.394$ ), higher $\mathrm{BMI}$ at the time of study (adjusted $\mathrm{OR}=1.426, \mathrm{CI}=1.215-1.674$ ). Being Malay was a protective factor (adjusted $\mathrm{OR}=0.264, \mathrm{CI}=00.102-0.685$ ) for abdominal obesity. These results suggest that care of the HIV-infected population must include intervention to address abdominal obesity in order to provide better quality of life.
\end{abstract}

Keywords: Abdominal obesity, HIV/AIDS, ARV treatment, Nutrition, Dietary intake, Waist-Hip ratio, Malaysia

\section{Introduction}

Acquired Immune Deficiency Syndrome (AIDS or Aids) is a rapidly growing global problem that is accompanied by high morbidity and mortality. According to the latest report (UNAIDS, 2008) the number of people living with the human immunodeficiency virus (HIV) in the world totaled 33 million people as of December 2007 of whom 5 million were in Asia. In Malaysia there were more than 80000 [52 000-120 000] 
people living with HIV (PLHIV) as of the end of 2008 (UNAIDS, 2008). Antiretroviral (ARV) drugs are the only medication available to inhibit viral replication and reduce morbidity and mortality due to AIDS in the absence of vaccination (WHO, 2000a). The strategy of free access to antiretroviral (ARV) treatments adopted by Malaysia has notably increased the survival rate as a result of a reduction in the incidence of opportunistic infections and also HIV/AIDS complications (Malaysia UNGASS Report, 2008).

On the other hand, ART (Antiretroviral Therapy) can cause a variety of side effects, some of them adversely affecting the nutritional status of PLHIV (WHO, 2007). Changes in body composition and metabolic complications such as dyslipidemia, insulin resistance (Miller et al., 2003; Richter et al., 2005; Hansen et al., 2009) and increased rate of cardiovascular disease (CVD) (Depairon et al., 2001; Baum et al., 2006; Sankatsing et al., 2009) are the most commonly quoted adverse nutritional effects on patients receiving highly active antiretroviral therapy (HAART). Related to this, abdominal obesity as a typically morphological abnormality has been observed among both HIV-positive men and women (Galli et al., 2003; Jaime et al., 2006) in many countries where HAART has been available for a long time. Two recent studies showed that $45.7 \%(\mathrm{n}=223)$ of Brazilian HIV+ (Jaime et al., 2006) and 30.7\% (n=471) of American HIV infected subjects (Mondy et al., 2007) had central obesity.

It is believed that protease inhibitors (PIs) are the main cause of morphologic changes in the form of fat accumulation (Carr, 2000; Martínez et al., 2001, Saves et al., 2002). Besides, other factors may contribute to fat redistribution including HIV infection related factors like severity and length of HIV infection (Lichtenstein et al., 2001), hypertriglyceridemia and insulin resistance (Martínez et al., 1999; Rodriguez-Guardado et al., 2001) and dietary intake (Hendricks et al., 2003; Jaime et al., 2006).

Abdominal obesity is defined as the localized accumulation of adipose tissue in abdomen irrespective of proportion to total body fat (NHI, 1998). In general, the presence of excess body fat around certain parts of the body, especially around the abdominal area is considered a risk factor for certain diabetes, metabolic syndrome and cardiovascular disease (Kannel et al., 1991, Denke et al., 1993; Insel et al., 2007).

Presently waist-hip circumference ratio (WHR) is not so often used for evaluating central adiposity in the general population and in its place waist circumference is the most widespread anthropometric measurement used. However waist hip ratio (WHR) is useful in detecting possible signs of excess fat deposition (lipodystrophy) in those infected with the HIV (Florindo et al., 2004; Dolan et al., 2005; Jaime et al., 2006).

The present study is aimed at estimating the prevalence of abdominal obesity and comparing the significantly associated factors between those with had abdominal obesity with those who did not. The study was also designed to predict those factors that have the potential to contribute to the development of abdominal obesity in PLHIV receiving HAART. This is the first study on abdominal obesity among PLHIV in Malaysia.

\section{Materials and Methods}

\subsection{Study design and sampling method}

Study subject involved a total of 340 adult HIV diagnosed patients aged 20 years or older undergoing treatment with at least one ARV drug, proportionally sampled from all PLHIV who were initially investigated between February and September, 2008, at Hospital Sungai Buloh, Malaysia. The missing data related to anthropometric measurements were the result of some conditions during clinical examinations including pregnancy (4 cases), inability to measure height and weight ( 2 cases) due to inappropriate position of subjects (sitting or lying down and not able to stand up).

Finally, the waist and hip measurements of 334 of studied population were measured for the calculation of waist-hip ratio (WHR). Patients were recruited when they were at the hospital for their normal follow-up. Patients who were undergoing treatment with b-blockers, diuretics, steroids, oral contraceptive pills, lipid-lowering and hyperglycemic agents, corticoids, anabolic steroids or growth hormones before and during ART as well as those who had active opportunistic diseases (infections or tumors) in the six months prior to the study as well as non Malaysians were also excluded. The process of sampling was applied on respondents' records. Before selecting respondents' records, the investigator used a sampling fraction in each stratum that was proportional to that of the total population. The investigator determined the total HIV respondents receiving antiretroviral medication till February 2008 at the infectious diseases clinic at Hospital Sungai Buloh, and then calculated the percentage in each ethnic group and gender. In order that the sample was well represented from the standpoint of gender and ethnicity a two-stage proportional stratified sampling method was applied with the Chinese making up 64.7\% (216 patients), and the Malay and Indians each making up 24.9\% (83patients) and $10.4 \%$ (35 patients) respectively. Meanwhile, $79.9 \%$ (267 patients) were male and $20.1 \%$ (67 patients) females. 


\subsection{Data collection}

The data collection was conducted in 29 weeks between February and September, 2008, at Hospital Sungai Buloh, Malaysia. A bi-lingual structured questionnaire (in Malay and English) was developed to obtain the information about socioeconomic status (gender, ethnicity, age, employment and educational level, monthly household income), medical history and health status (duration of HIV infection, current supplementation, history of drug abused, CD4 cell count and HIV viral load at start of medication and at time of the study) ARV regimen (line, length of time on ARV and exposure to AZT, d4T, PI). Informed written consents were obtained from the respondents by two trained assistants prior to taking measurements (all done by the principal investigator to reduce error) and conduct of interview.

Weight $(\mathrm{kg})$ was taken using the Tanita weighing scale that was calibrated weekly and height $(\mathrm{m})$ measures using a SECA body meter. Two weight and height measurements were taken and the average recorded. Body mass index (BMI, $\mathrm{kg} / \mathrm{m} 2$ ) was calculated according to the World Health Organization (WHO) criteria for classification (WHO, 2000b).

Body composition including total fat and total fat-free mass (lean mass) were measured using bioelectric impedance analyzer (BIA) BODYSTAT ${ }^{\circledR} 1500$. In accordance to the instructions in its manual, respondents were told the following; (a) not to eat or drink four hours before the test, (b) avoid heavy exercise 12 hours before testing, (c) to not drink alcohol within 24 hours of the test, (d) empty bladder completely prior to testing and (e) to avoid taking diuretics prior to testing unless instructed by the physician. Because all respondents had also to fast overnight (12 to 14 hours) for blood to be taken for various tests and therefore it was the best opportunity for the researcher to carry out the BIA at the same time.

Both waist and hip circumferences were measured using the SECA ${ }^{\circledR}$ (SECA, Germany) non stretchable tape to the nearest 0.1 centimeter. Waist circumferences were obtained by measuring the distance around the smallest area below the rib cage and above umbilicus (belly button). Hip circumference measurements were taken at the point yielding the maximum circumference over the buttocks with the tape in a horizontal plane, touching but not compressing the skin. The measurements were carried out twice, and then the average of the two readings was recorded as the final reading. All measurements were taken by the researched herself.

Abdominal obesity was defined as waist-to-hip ratio greater than 0.90 for men and 0.85 for women (WHO, 1998). Generally male waist circumference equal to or more than $102 \mathrm{~cm}$ and female waist circumference equal to or more than $88 \mathrm{~cm}$ were considered unhealthy (WHO, 1998).

Blood pressure was measured using digital blood pressure machine model (General Electric, DINAMAP ProCare 120). Blood pressures of respondents were measured in a sitting position on the right upper arm after a rest of a few minutes in the infectious disease clinic.

Biochemical assessment in adults included laboratory measurements of fasting lipid profile [Total Cholesterol (TC), LDL- Cholesterol (LDL-C) and HDL-Cholesterol (HDL-C)], fasting plasma glucose (FPG), CD4 cell count and HIV RNA load. All biochemical parameters were obtained from the computerized medical records of patients. The CD4 cell counts were categorized according to the standard of CENTRE FOR DISEASE CONTROL AND PREVENTION (CDC, 1993). Tests for HIV-RNA viral load was used to determine HIV RNA load during ARV medication and then classified using WHO (2006) references into undetectable level (value below 50 copies $/ \mathrm{mL}$ ) and detectable level (as equal or greater than 50 copies $/ \mathrm{mL}$ ).

The 24-hour dietary recall method of data collection required individuals to remember the specific foods and amount of food (macronutrient, micronutrient and total energy) they consumed in the past twenty-four hours. Detailed descriptions of all foods and beverages consumed including cooking methods were taken into account. Information such as ingredients of the cooked food and amount of raw food used in cooking were also obtained. Quantities of food consumed were estimated using household measures and were later entered into the data sheet. The twenty-four hour recalls were carried out over two days with one on a weekday and one in the weekend. Data obtained were analyzed based on the Malaysian food database using Nutritionist Pro software (First Data Bank, 2005). Malaysian food composition tables (Tee et al., 1997) were applied to measure the quantity of some food. If cooked dishes were not included in the database of Nutritionist Pro ${ }^{\mathrm{TM}}$ Software, Malaysian Food Composition database (Tee et al., 1997) were used to identify recipe for each dish and then the quantitative information was entered to Nutritionist Pro software. The average energy and nutrient content of the two days 24-houre dietary recall were used for statistical analysis. The dietary variables studied included consumption of energy (in $\mathrm{kcal}$ ), macronutrients (in g and \% energy), sodium and potassium. 


\subsection{Data analysis}

Statistical analysis was performed using SPSS statistical software (version 16.0). The association between abdominal obesity and demographic, clinical and anthropometric variables was assessed using the Chi-square test (categorical variables) and Independent Sample t-test (continuous variables) and Fisher's Exact test.

A multiple logistic regression model was used to predict the risk or protective factors for abdominal obesity adjusting for potential confounders, such as gender, age, ethnicity, years of education, ever abused drug (yes/no), line of ARV regimen, monthly household income (in Ringgit Malaysia- RM), length of time on ARV (Months), BMI $(\mathrm{kg} / \mathrm{m} 2)$ at start of medication and at the time of the study, CD4 cell count at the time of study and triglyceride, fasting plasma glucose $(\mathrm{mmol} / \mathrm{L})$, body fat mass $(\%)$, energy intake $(\mathrm{kcal})$, protein intake $(\mathrm{g})$, carbohydrate intake (g), fat intake (g), sodium ( $\mathrm{mg}$ ), potassium $(\mathrm{mg}), \%$ energy from protein, \% energy from carbohydrate and \% energy from total fat. The estimates were presented as odds ratio (OR) with a $95 \%$ confidence interval $(95 \% \mathrm{CI})$. Guidelines provided had stipulated that total carbohydrate intake should contribute $55-70 \%$, total fat $20-30 \%$, and protein $10-15 \%$ of total daily energy intake for the Malaysian adult population (NCCFN, 2005). Total energy requirements were increased by 10 percent (WHO, 2003) over the level of energy intake recommended for healthy non- HIV-infected persons of the same age (adults), sex, and physical activity level for asymptomatic patients in stage 1 AIDS (WHO, 2006).

\subsection{Ethical issue and Consent Form}

Ethical considerations and approvals to conduct the study were obtained from the following list of individuals/committees: (1) Medical Research Ethics Committee of the Faculty of Medicine and Health Science, University PUTRA Malaysia, (2) The director, Hospital Sungai Buloh, (3) The director, Hospital Selayang, (4) Clinical Research Center (CRC) of the Ministry of Health Malaysia, (5) National Institute of Health (NIH) Malaysia and (6) Ministry of Health Malaysia.

All participants were fully informed about the purpose of the study. Their anonymity was maintained by asking participants not to write their names on the questionnaire. Confidentiality was maintained by not identifying any responses and by reporting the information in a summary form. In additional, their participation in the study was on a voluntary basis, they can withdraw from the study at any time without affecting their treatment. All the respondents filled and signed a consent form before they were interviewed.

\section{Results}

\subsection{Prevalence of abdominal obesity}

Prevalence of abdominal obesity according to waist circumference and waist hip ratio is presented in Table1. The overall prevalence of abdominal obesity based on waist hip ratio was $36.5 \%$. The comparison of percentage distribution by characteristics revealed that a significantly higher percentage of Indians and Chinese, respondents who had no history of drug abuse, those currently exposure to a protease inhibitor (PI) agent, those respondents that were overweight/obese at start of medication or at the time of study had abdominal obesity (Table 2).

The comparison with the background of respondents as shown in Table 2 revealed that the respondents with abdominal obesity had significantly higher $(p<0.05)$ mean age, blood triglycerides, fasting plasma glucose, HDL-cholesterol, BMI at the start of medication and at the time of the study, waist circumference, waist hip ratio, body fat mass, systolic and diastolic blood pressure and also lower mean CD4 cell count at start of medication and body lean mass than those without abdominal obesity.

The comparison of mean dietary intakes for patients with and without abdominal obesity is presented in Table 3 . There were no significant differences in average dietary intake of various nutrirnts between two groups.

As shown in Table 4, the results of the final logistic regression models for selected variables found that before adjusting for covariates, age (unadjusted $\mathrm{OR}=1.050, \mathrm{CI}=1.023-1.078$ ), current exposure to PI (unadjusted $\mathrm{OR}=2.237, \mathrm{CI}=1.212-4.129$ ), higher triglycerides (unadjusted $\mathrm{OR}=1.192, \mathrm{CI}=1.032-1.378$ ), higher fasting plasma glucose (unadjusted $\mathrm{OR}=1.292, \mathrm{CI}=1.119-1.491$ ), higher $\mathrm{BMI}$ at start of medication (unadjusted $\mathrm{OR}=1.207, \mathrm{CI}=1.128-1.291$ ), higher $\mathrm{BMI}$ at the time of study (unadjusted $\mathrm{OR}=1.319, \mathrm{CI}=1.214-1.434$ ), higher $\mathrm{BMI}$ at the time of observation (unadjusted $\mathrm{OR}=1.044, \mathrm{CI}=1.012-1.078$ ) and higher body fat mass (unadjusted $\mathrm{OR}=1.044, \mathrm{CI}=1.012-1.078)$ significantly increased the risk of abdominal obesity. In contrast being Malay protected (unadjusted $\mathrm{OR}=0.471, \mathrm{CI}=0.266-0.834$ ) them against abdominal obesity. After adjusting for the covariates, a significant higher risk of abdominal obesity were observed in those who were older (adjusted $\mathrm{OR}=1.053, \mathrm{CI}=1.012-1.095$ ), those who had higher fasting plasma glucose (adjusted $\mathrm{OR}=1.189$, $\mathrm{CI}=1.014-1.394$ ), those with higher $\mathrm{BMI}$ at the time of observation (adjusted $\mathrm{OR}=1.426, \mathrm{CI}=1.215-1.674$ ) and being Malay was a protective factor (adjusted $\mathrm{OR}=0.264, \mathrm{CI}=00.102-0.685$ ) for abdominal obesity. 


\section{Discussion}

This study revealed that WHR is a more accurate anthropometric predictor of abdominal obesity than WC confirming studies by Florindo et al. (2004) and Jaime et al. (2006). Florinda and colleagues (2004) using computerized tomography of the abdomen (CTA) found that visceral fat had better association with the measurement of WHR $(r=0.74 ; p=0.009)$ than with the measurement of WC $(r=0.60 ; p=0.050)$ among men $(n=10)$ and women $(n=5)$ in Brazil. The main reason for this is the fact that PLHIV on medication experience morphological alterations including reduction in hip circumference due to lipoathrophy along with increase in waist circumference as a result of subcutaneous and/or visceral fat accumulation

Similarly, a high incidence of centralized distribution of adiposity has been observed among PLHIV under treatment with ARV regimen, (Schwenk et al., 2001; Dolan et al., 2005; Jaime et al., 2006; Sutinen \& Yki-Järvinen, 2007). Some previous studies (Miller et al., 1998; Carr, 2000; WHO, 2006) had attributed the increased risk of abdominal obesity mainly to the prescription of PIs.

Morphological abnormalities observed in subjects receiving ARV has been found to differ by gender as well as race/ethnicity. Some study of positive HIV infected subjects under ARV medication showed that abdominal fat and mean WHR/WC were higher in HIV positive men (Jacobson et al. 2005; Shah et al., 2005) or among HIV infected women (Jamie et al. 2006). In this study abdominal obesity was more prevalent among the women but the difference was not significant. Fasting hyperinsulinemia (Hadigan et al., 1999) in human immunodeficiency virus-infected women with the increased abdominal fat may be the possible explanations for tendency to progress an android body formation characterized by increased trunk fat. The finding of this research revealed that abdominal obesity was less prevalent among Malay and Chinese. Also, A number of researches revealed that Caucasian HIV positive women (Bausserman et al., 2004), African-American women and White men (Shen et al., 2006) had higher WC. Similarly, Kee et al. (2008) reported that among 32,900 Malaysian subjects, the prevalence of abdominal obesity was higher among the Indian (28.2\%) than Malays (18.6\%) and Chinese (14.1\%). It may be a reason for higher incidence of abdominal obesity among studied HIV subjects that was influenced by race/ethnicity differences in general population (Kee et al., 2008).

This study revealed that PLHIV on ARV experienced an increase in central adiposity with age confirming the findings of Martinez et al. (2001), Jaime et al. (2006). WHO (2006) also made mention of this in their guidelines on ARV for PLHIV. PLHIV as a relatively small portion of general population may experience the similar consequences of aging including deficiencies in growth hormone, dehydroepiandrosterone, testosterone and, decline in resting metabolism that may be accompanied with weight gain (Racette et al., 2003). Another factor that was associated with prevalence of abdominal obesity was CD4 cell count at the start of medication confirming the study by Mallon et al. (2003) and WHO (2006).

Higher LDL-cholesterol (Mallon et al., 2003), triglycerides (Kosmiski et al., 2001; Mallon et al., 2003; Guimarães et al., 2007), and lower HDL cholesterol (Kosmiski et al., 2001; Fessel et al., 2002; Mallon et al., 2003; Scherzer et al., 2008), FPG (Meininger et al., 2002; Guimarães et al., 2007) in blood were observed in patients with more abdominal adiposy. Similarly, Meininger et al. (2002) demonstrated that increasing in WHR $(\mathrm{CI}=18.6-136.1 ; p=0.011)$ is associated with incidence of fasting hyperinsulinemia (as predictor of elevated plasma glucose).

Joy et al. (2008) using linear regression model in the USA found that the relationship between BMI and abdominal fat accumulation was linear $(p<0.0001)$. In the other words, increase in BMI was accompanied with the increase in abdominal obesity. In terms of abdominal obesity, Jacobson et al. (2005) using multivariate analysis in USA found that greater body fat mass (relative risk $(\mathrm{RR})=3.1$, CI $=1.4-6.7 ; p<0.005$ ) was associated with the risk of fat deposition in abdomen and the respondents with higher percentage of body fat had more central fat deposition (waist-to-hip ratio of $>0.95 \mathrm{~cm}$ for men and of $>0.85 \mathrm{~cm}$ for women).

In addition, it was noted that increased WC, WHR and abdominal obesity occurred more frequently in individuals with hypertention, expressed by increased systolic and/or diastolic blood pressure (Sattler et al., 2001; Jung et al., 2004; Guimarães et al., 2007; Nyamdorj et al., 2008).

Contrary to some studies (Hendricks et al., 2003; Jaime et al., 2006), there were no significant difference in dietary intake between HIV infected subjects with and without abdominal obesity in this study. It seems that dietary factors did not play a key role in occurrence of this morphological abnormality.

One limitation of this study is that it is based on a cross-sectional design and the availability of longitudinal follow-up data can further explain and confirm the association of abdominal obesity with other factors. Another limitation was the fact that the result of this study only indicates abdominal obesity and nutritional factors of 
PLHIV receiving antiretroviral medication at Hospital Sungai Buloh and therefore it cannot be generalized to all PLHIV in Malaysia. In-spite of the advantages of using bioelectrical impedance analysis (BIA), it cannot measure regional body composition and thus was not used to measure abnormal body-fat deposition and this is a BIA measurement limitation. Consequently, the more advanced and precious medical instruments such as DEXA (Dual-Energy X-Ray Absorptiometry), MRI (Magnetic Resonance Imaging) or CT scan (Computed Tomography) are recommended. Since this study focused on fat deposition as abdominal obesity, these findings cannot be applicable to regional fat loss or fat atrophy.

The investigation on the incidence of morphological changes as fat atrophy and fat accumulation should be further studied to determine the prevalence of lipodystrophy. The estimated dietary intakes in this study were based on 24-hour recall and despite using trained interviewers inaccurate estimates and underreporting of food intake recall by respondents with little or no education was another limitation. Dietary data collected by 24-hour recall may be less accurate than food record data due to the inability of memory recall by older respondents as a result of their mental cognitive impairment (Gauthier et al., 2006), underreporting of consumed food by the obese due to desirability to eliminate unhealthy food such as fat (Tooze et al., 2007) and poorly educated respondents that may not reflect usual intake.

\section{Conclusion}

As a result of some complications associated with HIV infection and ARV medication including metabolic and morphological abnormalities that interfere with health status and quality of life of this population, further studies are needed to evaluate the impact of modifiable and preventive programs on morphologic and metabolic complications, their risk factors and risk of future chronic diseases in HIV infected subjects.

\section{Acknowledgments}

We thank the Department of Nutrition and Dietetics and also Faculty of Medicine and Health Sciences University Putra Malaysia, Hospital Sungai Buloh, Hospital Selayang, Clinical Research Center (CRC), National Institute of Health (NIH) and Ministry of Health Malaysia for approval to conduct the study. This study was funded by Malaysian AIDS Council (MAC) under the Ministry of Health, Malaysia, year 2006 grant. Special thanks also to Dr. Christopher Lee who accepted my master research project and provided me with the best research environment and support at Hospital Sungai Buloh.

I wish to thank Dr. Adeeba Kamaruzaman, President of the Malaysian AIDS Council (MAC) who assisted me in getting the funding and members of her staff, especially Miss. Ines Yap, Director, Evaluation \& Development Division and Mrs. Sivakami Visvalingam Senior Executive, Programme Development Department for their continuous support throughout research. I was so privileged to work with HIV infected people at Hospital Sungai Buloh who willingly participated in this study. Without their patience and cooperation I would not have been able to conduct this research.

\section{References}

Baum, M. K., Rafie, C., Lai, S., Xue, L., Sales, S., Page, J. B., et al. (2006). Coronary Heart Disease (CHD) risk factors and metabolic syndrome in HIV-positive drug users in Miami. American Journal of Infectious Disease, 2 (3), 173-179.

Bausserman, L. L., Tashima, K. T., DiSpigno, M., Maceroni, D., \& Carpenter, C. C. J. (2004). Racial differences in serum lipids in HIV+ women treated with protease inhibitor regimens. HIV Clinical Trials, 5 (6), 399-405.

Carr, A. (2000). HIV Protease Inhibitor-related lipodystrophy syndrome. Clinical Infectious Diseases, 30 (Suppl 2), S135-42.

Centre for Disease Control and Prevention (CDC). (1993). 1993 Revised classification system for HIV infection and expanded surveillance case definition for AIDS among adolescents and adults. Morbidity and Mortality Weekly Report, 41, (RR-17).

Denke, M. A., Sempos, Christopher T., Grundy, \& Scott M. (1993). Excess body weight: An Underrecognized contributor to high blood cholesterol levels in White American men. Archives of International Medicine, 153 (9), 1093-1103.

Depairon, M., Chessex, S., Sudre, P., Rodondi, N., Doser, N., Chave, J. P., et al. (2001). Premature atherosclerosis in HIV-infected individuals - focus on protease inhibitor therapy. AIDS, 15 (3), 329-334.

Dolan, S. E., Hadigan, C., Killilea, K. M., Sullivan, M. P., Hemphill, L., Lees, R. S., et al. (2005). Increased cardiovascular disease risk indices in HIV-infected women. Journal of Acquired Immune Deficiency Syndromes, 39 (1), 44-54. 
Fessel, W. J., Follansbee, S. E., \& Rego, J. (2002). High-density lipoprotein cholesterol is low in HIV-infected patients with lipodystrophic fat expansions: Implications for pathogenesis of fat redistribution. AIDS, 16 (13), 1785-1789.

First DataBank. (2005). Nutritionist Pro ${ }^{T M}$, Nutrition Analysis Software. San Bruno, CA 94066.

Florindo, A, A., Latorre Mdo, R., Santos, E. C., Borelli, A., Rocha Mde, S, Segurado, A. A. (2004). Validation of methods for estimating HIV/AIDS patients' body fat. Revista de Saúde Pública, 38 (5), 643-649.

Galli, M., Veglia, F., Angarano, G., Santambrogio, S., Meneghini, E., Gritti, F., et al. (2003). Gender differences in antiretroviral drug-related adipose tissue alterations: Women are at higher risk than men and develop particular lipodystrophy patterns. Journal of Acquired Immune Deficiency Syndromes, 34 (1), 58-61.

Gauthier, S., Reisberg, B., Zaudig, M., Petersen, R. C., Ritchie, K., Broich, K., et al. (2006). Mental mild cognitive impairment. The Lancet, 36 (9518), 1262-70.

Guimarães, M. M. M., de Oliveira Júnior A. R., Penido M. G., Queiroz L. C, Goulart E. M. A., Greco D. B., \& Machado, L. J. C. (2007). Ultrasonographic Measurement of Intra-Abdominal Fat Thickness in HIV-Infected Patients Treated or Not with Antiretroviral Drugs and Its Correlation to Lipid and Glycemic Profiles. Annals of Nutrition \& Metabolism 2007, 51 (1), 35-41.

Hadigan, C., Miller, K., Corcoran, C., Anderson, E., Basgoz, N., \& Grinspoon, S. (1999). Fasting hyperinsulinemia and changes in regional body composition in human immunodeficiency virus-infected women. The Journal of Clinical Endocrinology \& Metabolism, 84 (6), 1932-1937.

Hansen, B. R., Petersen, J., Haugaard, S. B., Madsbad, S., Obel, N., Suzuki, Y., et al. (2009). The prevalence of metabolic syndrome in Danish patients with HIV infection: The effect of antiretroviral therapy [Abstract]. HIV medicine, 9999, (9999), [Online] Available: http://www3.interscience.wiley.com/journal/122286621/abstract (June 2, 2009).

Hendricks, K. M., Dong, K. R., Tang, A. M., Ding, B., Spiegelman, D., Woods M. N., et al. (2003). High-fiber diet in HIV-positive men is associated with lower risk of developing fat deposition. American Journal of Clinical Nutrition, 78 (4) 790-795.

Insel, P., Turner, R. E., \& Ross, D. (2007). Nutrition ( $3^{\text {rd }}$ ed.). Sudbury, CA: Jones and Barlett.

Jacobson, D. L., Knox, T., Spiegelman, D., Skinner, S., Gorbach, S., \& Wanke, C. (2005). Prevalence of, evolution of, and risk factors for fat atrophy and fat deposition in a cohort of HIV-infected men and women. Clinical Infectious Diseases, 40 (12), 1837-45.

Jaime, P. C., Florindo, A. A., Latorre, M. R. D. O., \& Segurado, A. A. C. (2006). Central obesity and dietary intake in HIV/AIDS patients. Rev Saúde Pública, 40 (4), 634-40.

Joint United Nations Programme on HIV/AIDS (UNAIDS). (2008). Report on the global HIV/AIDS epidemic 2008. Geneva: UNAIDS.

Joy, T., Keogh, H. M., Hadigan, C., Lee, H., Dolan, S. E., Fitch, K., et al. (2008). Relation of body composition to body mass index in HIV-infected patients with metabolic abnormalities. Journal of Acquired Immune Deficiency Syndromes, 47 (2), 174-184.

Jung, O., Bickel, M., Ditting, T., Rickerts, V., Welk, T., Helm, E. B., et al. (2004). Hypertension in HIV-1-infected patients and its impact on renal and cardiovascular integrity. Nephrol Dial Transplant, 19 (9), 2250-2258

Kannel, W. B., Cupples, L. A., Ramaswami, R., Stokes, III J., Kreger, B. E., \& Higgins, M. (1991). Regional obesity and risk of cardiovascular disease; the Framingham study. Journal of Clinical Epidemiology, 44,183-190.

Kee, C. C., Jamaiyah, H., Noor Safiza, M. N., Geeta, A., Khor, G. L., Suzana, S., et al. (2008). Abdominal obesity in Malaysian adults: National Health and Morbidity Survey III (NHMS III, 2006). Malaysian Journal of Nutrition, 14 (2), 125-135.

Kosmiski, L. A., Kuritzkes, D. R., Lichtenstein, K. A., Glueck, D. H. Gourley, P. J., et al. (2001). Fat distribution and metabolic changes are strongly correlated and energy expenditure is increased in the HIV lipodystrophy syndrome. AIDS, 15 (15), 1993-2000.

Lichtenstein, K. A., Warda, D. J., Moormanb, A. C., Delaneyb, K. M., Young, B., Palella, F. J., et al. (2001). Clinical assessment of HIV-associated lipodystrophy in an ambulatory population. AIDS, 15 (11), 1389-1398. 
Mallon, P. W. G., Miller, J., Cooper, D. A., \& Carr, A. (2003). Prospective evaluation of the effects of antiretroviral therapy on body composition in HIV-1-infected men starting therapy. AIDS, 17 (7), 17971-979.

Martínez, E., Conget, I., Lozano, L., Casamitjana, R., \& Gatell, J. M. (1999). Reversion of metabolic abnormalities after switching from HIV-1 protease inhibitors to nevirapine. AIDS, 13 (7), 805-810.

Martínez, E., Mocroft A., García-Viejo M. A., Pérez-Cuevas, J. B., Blanco J. L., Mallolas, J., et al. (2001). Risk of lipodystrophy in HIV-1-infected patients treated with protease inhibitors: a prospective cohort study. The Lancet, 357 (9256), 592-598.

Meininger, G., Hadigan, C., Rietschel, P., \& Grinspoon, S. (2002). Body-composition measurements as predictors of glucose and insulin abnormalities in HIV-positive men. American Journal of Clinical Nutrition, 76 (2), 460-465.

Miller, J., Carr, A., Emery, S., Law, M., Mallal, S., Baker, D., et al. (2003). HIV lipodystrophy: Prevalence, severity and correlates of risk in Australia. HIV Medicine, 4 (3), 293-301.

Miller, K. D., Jones, E., Yanovski, J. A., Shankar, R., Feuerstein, I., \& Falloon, J. (1998). Visceral abdominal-fat accumulation associated with use of indinavir. The Lancet, 351 (9106), 871-875.

Mondy, K., Overton, E. T., Grubb, J., Tong, S., Seyfried, W., Powderly, W., et al. (2007). Metabolic syndrome in HIV-infected patients from an urban, Midwestern US outpatient population. Clinical Infectious Diseases, 44 (5), 726-34.

National Coordinating Committee on Food and Nutrition (NCCFN). (2005). Recommended Nutrient Intakes for Malaysia (RNI): A report of the technical working group on nutritional guidelines. Kuala Lumpur: Ministry of Health Malaysia.

National Heart, Lung, and Blood Institute; National Institutes of Diabetes and Digestive and Kidney Diseases. (NHI). (1998). Clinical guidelines on the identification, evaluation and treatment of overweight and obesity in adults. Bethesda: National Institutes of Health, (NHI Publication 4083).

Nyamdorj, R., Qiao, Q., Söderberg, S., Pitkäniemi, J., Zimmet, P., Shaw, J., et al. (2008). Comparison of body mass index with waist circumference, waist-to-hip ratio, and waist-to-stature ratio as a predictor of hypertension incidence in Mauritius. Journal of Hypertension, 26 (5), 866-870.

Racette, S. B,, Deusinger, S. S., \& Deusinger, R. H. (2003). Obesity: overview of prevalence, etiology, and treatment. Physical Therapy, 83 (3), 276-288.

Richter, A., Pladevall, M., Manjunath, R., Lafata, J. E., Xi, H., Simpkins, J., et al. (2005). Patient characteristics and costs associated with dyslipidaemia and related conditions in HIV-infected patients: A retrospective cohort study. HIV Medicine, 6 (2), 79-90.

Rodriguez-Guardado, A., Maradona, J. A., Carton, J. A., \& Asensi, V. (2002). Triglyceride increase can predict lipodystrophy in HIV patients under highly active antiretroviral therapy. AIDS, 16 (10), 1434-1436.

Sankatsing, R. R., Wit, F. W., Vogel, M., de Groota, E., Brinkmane, K., Rockstrohd, J. K., et al. (2009). Increased carotid intima-media thickness in HIV patients treated with protease inhibitors as compared to non-nucleoside reverse transcriptase inhibitors. Circulation, 202 (2), 589-595.

Sattler, F. R., Qian, D., Louie, S., Johnson, D., Briggs, W., DeQuattro V., et al. (2001). Elevated blood pressure in subjects with lipodystrophy. AIDS, 15 (15), 2001-2010.

Savès, M., Raffi, F., Capeau, J., Rozenbaum, J., Ragnaud, J. M., Perronne, C., et al. (2002). The Antiproteases Cohort (APROCO) Study Group. Factors related to lipodystrophy and metabolic alterations in patients with human immunodeficiency virus infection receiving highly active antiretroviral therapy. Clinical Infectious Diseases, 34 (15 May), 1396-1405.

Scherzer, R., Shen, W., Bacchetti, P., Kotler, D., Lewis, C. E., Shlipak, M. G., et al. (2008). Simple anthropometric measures correlate with metabolic risk indicators as strongly as magnetic resonance imaging-measured adipose tissue depots in both HIV-infected and control subjects. The American Journal of Clinical Nutrition, 87 (6), 1809-1817.

Schwenk, A., Breuer, P., Kremer, G., \& Ward, L. (2001). Clinical assessment of HIV-associated lipodystrophy syndrome: Bioelectrical impedance analysis, anthropometry and clinical scores. Clinical Nutrition, 20 (3), 243-249. 
Shah, M., Tierney, K., Adams-Huet, B., Boonyavarakul, A., Jacob, K., Quittner, C., et al. (2005). The role of diet, exercise and smoking in dyslipidaemia in HIV-infected patients with lipodystrophy. HIV Medicine, 6 (4), 291-298.

Shen, W., Punyanitya, M., Chen, J., Gallagher, D., Albu, J., Pi-Sunyer, X., et al. (2006). Waist circumference correlates with metabolic syndrome indicators better than percentage fat. Obesity, 14 (4), 727-736.

SPSS 16.0. (2007). Statistical package for the social sciences 16.0. Chicago, Illinois: SPSS Inc.

Sutinen, J., \& Yki-Järvinen, H. (2007). Increased resting energy expenditure, fat oxidation, and food intake in patients with highly active antiretroviral therapy-associated lipodystrophy. American Journal of Physiology Endocrinology and Metabolism, $292 \quad$ (3), E687-E692. [Online] Available: http://ajpendo.physiology.org/cgi/reprint/292/3/E687. (April 16, 2009).

Tee, E. S., Ismail, M. N., Nasir, M. A., \& Khatijah, I. (1997). Nutrient composition of Malaysian food (4 ${ }^{\text {th }}$ ed.). Malaysian Food Composition Database Programme, Institute for Medical Research, Kuala Lumpur.

Tooze, J. A. Vitolines, M. Z., Smith, S. L., Arcury, T. A., Davis, C. C., Bell, R. A., et al. (2007). High levels of low energy reporting on 24-houre recalls and three questionnaires in an elderly low-socioeconomic status population. The Journal of Nutrition, 137 (5), 1286-1293.

UNGASS Country Progress Report 2008: Malaysia. (2008). Malaysia: AIDS/STD Section of the Disease Control Division, Ministry of Health, Malaysia.

World Health Organization (WHO). (1998). Obesity: Preventing and managing the global epidemic. Report on a WHO Consultation on Obesity, Geneva, 3-5 June 1997. Geneva: WHO.

World Health Organization (WHO). (2000a). Safe and Effective Use of Antiretroviral Treatments in Adults with particular references to resource limited settings. Geneva: WHO.

World Health Organization (WHO). (2000b). Obesity: Preventing and managing the global epidemic. Report on a WHO Consultation on Obesity. Geneva: WHO.

World Health Organization (WHO). (2003). Nutrient Requirements for People Living with HIV/AIDS: Report of a technical consultation. Geneva: WHO.

World Health Organization (WHO). (2006). Antiretroviral therapy for HIV infection in adults and adolescents: Recommendations for a public health approach-(Rev. 2006). Geneva: WHO.

World Health Organization (WHO). (2007). Management of HIV infection and antiretroviral therapy in adults and adolescents: A clinical manual (Technical Publication Series No. 58). New Delhi: WHO.

Table 1. Prevalence of Abdominal Obesity According to Waist Circumference and Waist Hip Ratio

$(\mathrm{N}=334)$

\begin{tabular}{|l|c|c|}
\hline Abdominal Obesity & $\begin{array}{c}\text { Waist Circumference } \\
\text { a } \\
(\mathrm{n}=334)\end{array}$ & $\begin{array}{c}\text { Waist Hip Ratio }^{\S} \\
(\mathrm{n}=334)\end{array}$ \\
\hline Yes & $15(4.5)$ & $122(36.5)$ \\
\hline No & $319(95.5)$ & $212(63.5)$ \\
\hline
\end{tabular}

${ }^{a}$ Abdominal obesity: Female WC $\geq 88 \mathrm{~cm}$ and Male WC $\geq 102 \mathrm{~cm}(\mathrm{WHO}, 1998$

${ }^{\S}$ Abdominal obesity: Female WHR $>0.85$ and Male WHR $>0.9$ (WHO, 1998) 
Table 2. Population characteristics according to the presence of abdominal obesity $(n=334)$

\begin{tabular}{|c|c|c|c|}
\hline \multirow{2}{*}{$\begin{array}{l}\text { Characteristic } \\
\text { Abdominal Obesity }\end{array}$} & \multicolumn{2}{|c|}{$\begin{array}{c}\text { Abdominal Obesity } \\
\text { No. }(\%)\end{array}$} & \multirow[t]{2}{*}{$\begin{array}{c}* P-\text { Valu } \\
\text { e }\end{array}$} \\
\hline & No $(n=212)$ & Yes $(n=122)$ & \\
\hline \multicolumn{4}{|l|}{ Gender } \\
\hline Male & $172(64.4)$ & $95(35.6)$ & \\
\hline Female & $40(59.7)$ & $27(40.3)$ & $0.473^{\mathrm{a}}$ \\
\hline \multicolumn{4}{|l|}{ Ethnicity** } \\
\hline Chinese & $129(59.7)$ & $87(40.3)$ & \\
\hline Malay & $63(75.9)$ & $20(24.1)$ & \\
\hline Indian & $20(57.1)$ & $15(42.9)$ & $0.024^{\mathrm{a}}$ \\
\hline \multicolumn{4}{|l|}{ Educational Level (Years) } \\
\hline No Formal Education & $4(57.1)$ & $3(42.9)$ & \\
\hline $1-9$ & $123(62.1)$ & $75(37.9)$ & \\
\hline$=>10$ & $85(65.9)$ & $44(34.1)$ & $0.725^{\S}$ \\
\hline \multicolumn{4}{|l|}{ Employment Status } \\
\hline Employed (Full and Part Time) & $128(65.6)$ & $67(34.4)$ & \\
\hline Unemployed & $72(60.0)$ & $48(40.0)$ & \\
\hline Self employed & $12(63.2)$ & $7(36.8)$ & $0.600^{\mathrm{a}}$ \\
\hline \multicolumn{4}{|l|}{ Monthly Household Income } \\
\hline $\mathrm{RM}<1000$ & $95(65.1)$ & $51(34.9)$ & \\
\hline RM 1000-2000 & $66(64.7)$ & $36(35.3)$ & \\
\hline$=>$ RM 2000 & $51(59.3)$ & $35(40.7)$ & $0.646^{\mathrm{a}}$ \\
\hline \multicolumn{4}{|c|}{ Duration of HIV Infection (Years) } \\
\hline $1-5$ & $98(62.4)$ & $59(37.6)$ & \\
\hline $6-10$ & $74(60.2)$ & $49(39.8)$ & \\
\hline$=>10$ & $36(75.0)$ & $12(25.0)$ & $0.182^{\mathrm{a}}$ \\
\hline \multicolumn{4}{|l|}{ Current Supplementation } \\
\hline No & $149(60.8)$ & $96(39.2)$ & \\
\hline Yes & $63(70.8)$ & $26(29.2)$ & $0.094^{\mathrm{a}}$ \\
\hline \multicolumn{4}{|l|}{ Ever Drug Abused** } \\
\hline No & $167(60.1)$ & $111(39.9)$ & \\
\hline Yes & $145(80.4)$ & $11(19.6)$ & 0.004 \\
\hline \multicolumn{4}{|c|}{ CD4 Cell Count at Start of Medication } \\
\hline$<200$ cells $/ \mathrm{mm}^{3}$ & $145(62.0)$ & $89(38.0)$ & \\
\hline $200-499$ cells $/ \mathrm{mm}^{3}$ & $50(76.9)$ & $15(23.1)$ & \\
\hline$=>500$ cells $/ \mathrm{mm}^{3}$ & $4(80.0)$ & $1(20.0)$ & $0.052^{\S}$ \\
\hline \multicolumn{4}{|c|}{ CD4 Cell Count at Time of Study } \\
\hline$<200$ cells $/ \mathrm{mm}^{3}$ & $36(17.0)$ & $22(72.9)$ & \\
\hline $200-499$ cells $/ \mathrm{mm}^{3}$ & $112(52.8)$ & $68(47.2)$ & \\
\hline$=>500$ cells $/ \mathrm{mm}^{3}$ & $64(30.2)$ & $31(69.8)$ & $0.674^{\mathrm{a}}$ \\
\hline \multicolumn{4}{|c|}{ Viral Load at Start of Medication } \\
\hline$<100,000$ copies $/ \mathrm{mL}$ & $76(70.4)$ & $32(29.6)$ & \\
\hline$\geq 100,000$ copies $/ \mathrm{mL}$ & $62(62.6)$ & $37(37.4)$ & $0.238^{\mathrm{a}}$ \\
\hline \multicolumn{4}{|l|}{ Viral Load at Time of Study } \\
\hline$<50$ copies $/ \mathrm{mL}$ & $185(64.0)$ & $104(36.0)$ & \\
\hline$\geq 50$ copies $/ \mathrm{mL}$ & $27(60.0)$ & $18(40.0)$ & $0.603^{\mathrm{a}}$ \\
\hline \multicolumn{4}{|c|}{ Length of Time on ARV (Months) } \\
\hline$<6$ & $8(50.0)$ & $8(50.0)$ & \\
\hline$\geq 6$ & $201(64.0)$ & $113(36.0)$ & $0.257^{\mathrm{a}}$ \\
\hline \multicolumn{4}{|l|}{ Line of Antiretroviral Regimen } \\
\hline First Line & $110(67.1)$ & $54(32.9)$ & \\
\hline Changed First Line & $101(60.1)$ & $67(39.9)$ & $0.188^{\mathrm{a}}$ \\
\hline
\end{tabular}




\begin{tabular}{|c|c|c|c|c|c|}
\hline \multicolumn{6}{|l|}{ Exposure to AZT } \\
\hline No & \multicolumn{2}{|c|}{$103(62.1)$} & \multicolumn{2}{|c|}{$54(37.9)$} & \\
\hline Yes & \multicolumn{2}{|c|}{$105(65.6)$} & \multicolumn{2}{|c|}{$64(34.4)$} & $0.514^{\mathrm{a}}$ \\
\hline \multicolumn{6}{|l|}{ Exposure to d4T } \\
\hline No & \multicolumn{2}{|c|}{$108(62.1)$} & \multicolumn{2}{|c|}{$66(37.9)$} & \\
\hline Yes & \multicolumn{2}{|c|}{$100(65.8)$} & \multicolumn{2}{|c|}{$52(34.2)$} & $0.486^{\mathrm{a}}$ \\
\hline \multicolumn{6}{|l|}{ Exposure to PI** } \\
\hline No & \multicolumn{2}{|c|}{$188(66.4)$} & \multicolumn{2}{|c|}{$95(33.6)$} & \\
\hline Yes & \multicolumn{2}{|c|}{$23(46.9)$} & \multicolumn{2}{|c|}{$26(53.1)$} & $0.009^{\mathrm{a}}$ \\
\hline \multicolumn{6}{|l|}{ BMI at Start of Medication ** } \\
\hline Underweight $\left(\mathrm{BMI}<18.50 \mathrm{Kg} / \mathrm{m}^{2}\right)$ & \multicolumn{2}{|c|}{$56(82.4)$} & \multicolumn{2}{|c|}{$12(17.6)$} & \\
\hline Normal (BMI $\left.18.5-24.99 \mathrm{Kg} / \mathrm{m}^{2}\right)$ & \multicolumn{2}{|c|}{$136(65.4)$} & \multicolumn{2}{|c|}{$72(34.6)$} & \\
\hline \multirow[t]{2}{*}{ Overweight/Obese $\left(\mathrm{BMI} \geq 18.5-24.99 \mathrm{Kg} / \mathrm{m}^{2}\right)$} & \multicolumn{2}{|c|}{$20(34.5)$} & \multicolumn{2}{|c|}{$38(65.5)$} & 0.0001 \\
\hline & \multicolumn{4}{|c|}{ Mean; Standard deviation } & \\
\hline Age (Years) *** & 40.66; & 8.73 & 44.44; & 8.68 & 0.0001 \\
\hline $\begin{array}{l}\text { Number of years of formal education } \\
\text { (Years) }\end{array}$ & 7.96 & 4.71 & 7.76 & 4.26 & 0.692 \\
\hline $\begin{array}{l}\text { Household Income Per Month } \\
\text { (RM) }\end{array}$ & $1,143.07$ & $1,060.08$ & $1,311.35$ & $1,570.14$ & 0.293 \\
\hline Duration of HIV Infection (Years) & 6.10 & 4.14 & 5.67 & 3.48 & 0.346 \\
\hline $\begin{array}{l}\text { CD4 cell count at Start of Medication } \\
\left(\text { cells } / \mathbf{m m}^{3}\right) * * *\end{array}$ & 129.42; & 119.88 & 97.73; & 99.53 & 0.015 \\
\hline $\begin{array}{l}\text { CD4 cell count at the Time of Study } \\
\left(\text { cells } / \mathrm{mm}^{3}\right)\end{array}$ & 402.02; & 222.10 & 403.21; & 220.29 & 0.963 \\
\hline Viral Load at Start Medication (copies/mL) & 269,741.83; & $695,459.80$ & 412,087.42; & $959,751.22$ & 0.225 \\
\hline $\begin{array}{l}\text { Viral Load at the Time of Study } \\
\text { (copies/mL) }\end{array}$ & 780.30 & $5,894.72$ & $2,491.73$ & $20,002.51$ & 0.246 \\
\hline Length of Time on ARV (Months) & 42.41 & 33.77 & 45.92 & 34.12 & 0.364 \\
\hline Total Cholesterol (mmol/L) & 5.63 & 1.24 & 5.75 & 1.11 & 0.385 \\
\hline LDL-cholesterol (mmol/L) & 3.41 & 1.12 & 3.47 & 1.10 & 0.646 \\
\hline HDL-cholesterol $(\mathrm{mmol} / \mathrm{L}) * * *$ & 1.20 & 0.37 & 1.08 & 0.33 & 0.005 \\
\hline Triglycerides $(\mathrm{mmol} / \mathrm{L}) * * *$ & 2.23 & 1.57 & 2.68 & 1.60 & 0.014 \\
\hline Fasting Plasma Glucose $(\mathrm{mmol} / \mathrm{L}) * * *$ & 5.34 & 1.65 & 6.28 & 2.48 & 0.0001 \\
\hline BMI at the Start of Medication $\left(\mathrm{Kg} / \mathrm{m}^{2}\right)^{* * *}$ & 20.52 & 3.21 & 23.24 & 4.72 & 0.0001 \\
\hline BMI at the Time of Study $\left(\mathrm{Kg} / \mathrm{m}^{2}\right)^{* * *}$ & 21.02 & 3.11 & 24.04; & 3.82 & 0.0001 \\
\hline Waist Circumference $(\mathbf{c m}) * * *$ & 75.83 & 7.29 & 87.17 & 8.52 & 0.0001 \\
\hline Hip Circumference (cm)*** & 90.32 & 6.64 & 91.95; & 7.91 & 0.044 \\
\hline WHR (ratio) ${ }^{* * *}$ & 83.91; & 4.40 & 94.83; & 4.92 & 0.0001 \\
\hline Body Fat Mass Percentage $(\%)^{* * *}$ & 20.65 & 6.85 & 22.83 & 7.26 & 0.006 \\
\hline Body Lean Mass percentage $(\%)^{* * *}$ & 79.44 & 6.95 & 77.19 & 7.23 & 0.005 \\
\hline Systolic Blood Pressure $(\mathrm{mm} \mathrm{Hg})^{* * *}$ & 126.75 & 18.80 & 132.78; & 19.45 & 0.006 \\
\hline Diastolic Blood Pressure $(\mathrm{mm} \mathrm{Hg}) * * *$ & 75.10 & 11.24 & 79.03 & 11.97 & 0.003 \\
\hline
\end{tabular}

Statistically significant difference $(* *$ Chi-square test for frequencies, ***Independent sample t-test for means), $* p<0.05$.

${ }^{\mathrm{a}}$ Chi-square test for frequencies, ${ }^{\S}$ Fisher's Exact Test. 
Table 3. Dietary intake of the population according to the presence of abdominal obesity

$$
(\mathrm{n}=334)
$$

\begin{tabular}{|c|c|c|c|c|c|}
\hline \multirow[b]{2}{*}{ Characteristic } & \multicolumn{4}{|c|}{ Abdominal obesity } & \multirow[t]{2}{*}{$* P$-Value } \\
\hline & \multicolumn{2}{|c|}{ No $(n=212)$} & \multicolumn{2}{|c|}{ Yes $(n=122)$} & \\
\hline & \multicolumn{4}{|c|}{ Mean; Standard deviation } & \\
\hline Energy (kcal) & 1461.06; & 416.76 & 1414.99; & 344.34 & 0.277 \\
\hline Protein (g) & 67.45 & 24.61 & 66.33 & 24.07 & 0.688 \\
\hline Carbohydrate (g) & 172.27 & 46.67 & 167.33 & 36.48 & 0.284 \\
\hline Total Fat (g) & 55.85 & 23.53 & 53.12 & 20.25 & 0.266 \\
\hline Sodium (mg) & 1966.35; & 883.63 & 2080.58 & 758.59 & 0.232 \\
\hline Potassium (mg) & 1466.82; & 1019.66 & 1302.56; & 449.23 & 0.093 \\
\hline \% Energy from Protein & 18.39 & 3.82 & 18.61 & 4.22 & 0.629 \\
\hline$\%$ Energy from Carbohydrate & 48.02 & 8.06 & 48.28; & 8.25 & 0.779 \\
\hline \% Energy from Fat, total & 33.56 & 6.80 & 32.85 & 7.35 & 0.369 \\
\hline
\end{tabular}

Statistically significant difference (Independent sample t-test for means): ${ }^{*} p<0.05$.

Table 4. OR (95\% CI) for the abdominal obesity from logistic regression analysis for selected variables

\begin{tabular}{|c|c|c|c|c|}
\hline Characteristic & $\begin{array}{c}\text { Unadjusted OR } \\
(95 \% \mathrm{CI})\end{array}$ & P-Value & $\begin{array}{l}\text { Adjusted OR } \\
(95 \% \mathrm{CI})\end{array}$ & $P$-Value \\
\hline Age & $1.050(1.023-1.078)$ & $0.0001 *$ & $1.053(1.012-1.095)$ & $0.010^{*}$ \\
\hline \multicolumn{5}{|l|}{ Ethnicity } \\
\hline Chinese & 1.00 & $0.027 *$ & 1.00 & $0.023^{*}$ \\
\hline Malay & $0.471(0.266-0.834)$ & $0.010^{*}$ & $0.264(0.102-0.685)$ & $0.006^{*}$ \\
\hline Indian & $1.112(0.540-2.291)$ & 0.773 & $0.593(0.188-1.871)$ & 0.372 \\
\hline \multicolumn{5}{|l|}{ Ever Abused Drugs } \\
\hline \multicolumn{5}{|l|}{ No } \\
\hline Yes & $0.368(0.182-0.742)$ & $0.005^{*}$ & $0.610(0.228-1.637)$ & 0.327 \\
\hline \multicolumn{5}{|l|}{ Current Exposure to PI } \\
\hline No & 1.00 & & 1.00 & \\
\hline Yes & $2.237(1.212-4.129)$ & 0.010 & $2.112(1.108-3.821)$ & 0.216 \\
\hline Triglycerides & $1.192(1.032-1.378)$ & $0.017 *$ & $1.033(0.854-1.250)$ & 0.738 \\
\hline Fasting Plasma Glucose & $1.292(1.119-1.491)$ & $0.0001 *$ & $1.189(1.014-1.394)$ & $0.033 *$ \\
\hline BMI at Start of Medication & $1.207(1.128-1.291)$ & $0.0001 *$ & $0.986(0.877-1.109)$ & 0.817 \\
\hline BMI at the Time of Study & $1.319(1.214-1.434)$ & $0.0001 *$ & $1.426(1.215-1.674)$ & $0.0001 *$ \\
\hline Body Fat Mass (\%) & $1.044(1.012-1.078)$ & $0.007 *$ & $1.002(0.936-1.072)$ & 0.962 \\
\hline
\end{tabular}

Adjusted for gender, age, ethnicity, years of education, ever abused drug (yes/no), line of ARV regimen, monthly household income (in Ringgit Malaysia- RM), length of time on ARV (Months), BMI (kg/m2) at start of medication and at the time of the study, CD4 cell count at the time of study and triglyceride, fasting plasma glucose $(\mathrm{mmol} / \mathrm{L})$, body fat mass $(\%)$, energy intake $(\mathrm{kcal})$, protein intake $(\mathrm{g})$, carbohydrate intake $(\mathrm{g})$, fat intake (g), $\%$ energy from protein, $\%$ energy from carbohydrate, $\%$ energy from total fat. 